\title{
THE UNEXPECTED CARDIOPROTECTION BY EPIGENETIC FOODS
}

\section{Vincenzo Lionetti}

\author{
Laboratory of Translational Critical Care Medicine, Institute of Life Sciences, Scuola \\ Superiore Sant'Anna, Pisa, Italy
}

\begin{abstract}
Epigenetic changes affect the gene expression profile of cells without altering the DNA sequence in response to different environmental stimuli, such as the diet. Several dietary plant compounds have the epigenetic ability to prevent both the onset and the progression of different diseases, including cardiovascular diseases that are one of the most common in the world. Heart failure following perioperative myocardial infarction is a complex clinical syndrome without cure, also affecting high-risk patients undergoing non-cardiac surgery. It is characterized by serious decay of cardiac pump function as a result of ongoing remodelling of the myocardium. Despite the increasing use of conventional medications has reduced the mortality of patients with myocardial infarction, the outcome remains unpredictable so far. The past three decades have witnessed incessant research aimed at protecting the adult myocardium against ischemic injury, but the development of effective strategies to prevent the maladaptive tissue remodelling is still a desirable achievement. Recent findings reveal that the dietary intake of natural bioactive components with known antioxidant activity improves the intercellular communication and increases the tolerance of both cardiomyocytes and coronary endothelial cells against the ischemic microenvironment. The Epigenetic activation of rescue genes prevents the decay of function of the abovementioned cardiac cells. Consequently, this scenario would reduce the myocardial accumulation of collagen responsible for the tightening of the heart walls. Whereas the noninvasive delivery of cardioprotectant epigenetic compounds through diet is a promising approach, regulatory mechanisms need to be unravelled.
\end{abstract}

Key words: epigenetics; myocardial remodelling; cardioprotection; diet.

\section{INTRODUCTION}

Ischemic heart failure (HF) is a common complex clinical syndrome following myocardial infarction and is characterized by cardiac and non-cardiac features [1]. It is also the cause of mortality in high-risk patients undergoing non cardiac surgery [2]. Despite the wide use of different drugs, such as beta-blockers, angiotensin-converting enzyme inhibitors, angiotensin receptor blockers, diuretics, or of devices, such as implantable cardioverter-defibrillator and left ventricular assist devices [3], the 5-year survival is worse than cancer. The past few decades have witnessed incessant research aimed at protecting the adult myocardium against ischemic injury, but the development of effective strategies to prevent the maladaptive tissue remodelling is still a desirable achievement [4]. Therefore, it is clinically relevant to address further studies to dissect alternative pathophysiological issues, such as cellto-cell and cell-to-microenvironment cross-talk during the exposure to ischemic insult. Epigenetic modifications mediate mechanisms underline cellular tolerance against ischemic microenvironment, as cell survival and angiogenesis [5]. Despite the threshold of adaptive epigenetic effects is difficult to be safely modulated by synergistic drug combinations, the intramyocardial delivery of low doses of specific natural compounds has protected the ischemic myocardium through the modification of the epigenetic profile of cardiomyocytes, endothelial and interstitial cells [6]. Our first experimental evidence demonstrates the feasibility of cardioprotection by biocative compounds also present at higher concentrations in conventional plant foods named functional foods. To date, the regular intake of functional foods may be helpful to reduce cardiovascular risk factors [7] and to prevent the onset of the remodelling process of ischemic myocardium.

\section{OVERVIEW OF MYOCARDIAL TARGETS OF CARDIOPROTECTION}

The cardiac remodeling recapitulates cellular, interstitial, molecular and genetic changes after an initial injury.

Correspondence to:

Vincenzo Lionetti

TRANCRILAB - Laboratory of Translational Critical Care Medicine, Institute of Life Sciences, Scuola Superiore Sant'Anna Piazza Martiri della Libertà 33, 56127 Pisa, Italy

E-mail: v.lionetti@sssup.it 
The cardiac remodelling process itself is compensatory at early stage and detrimental in the long term [8]. The early inflammatory cell-mediated response is helpful to remove cell debris and to counteract the release of proapoptotic mediators, which leads to the activation of endothelial cells and fibroblasts to form new vessels and to promote adaptive hypertrophy respectively. Afterwards, collagen-rich scar replaces the loss of mature myocardium. The chaotic and rapid stimulation of intracellular pathways triggers cardiomyocytes and progenitor cells death, rarefies the native net of the coronary microcirculation, which is replaced by immature vessels, and deregulates the extracellular matrix turnover as well. This rescue scenario becomes over time a vicious circle leading to irreversible myocardial damage. Specific targets for the prevention of cardiac failure will be revised within interplay between dynamic and pleiotropic signaling pathways.

\section{THE SURVIVAL OF CARDIOMYOCYTES AND PROGENITOR CELLS}

Cardiac progenitor cells and cardiomyocytes survive in the presence of hostile microenvironment by multiple mechanisms and the magnitude of cell survival varies regardless the etiology and exposition time. The regulation of survival of cardiac cells is very important both to maintain the homeostasis of normal adult myocardium [9] and to limit the remodeling process during the exposure to insults [10-14]. To date, the prosurvival pathways counteract different form of cell death, such as apoptosis, oncosis and autophagy, in normal and injured adult myocardium [15].

Apoptosis is an active and highly regulated biological process. Two main apoptotic pathways transduce death signals in cardiac cells: i) the intrinsic pathway occurs through the opening of the mitochondrial permeability transition pore or the rupture of outer mitochondrial membrane. The cleavage of caspase-9/caspase- 3 cascade is mediated by cytochrome c, which is released by mitochondria after exposure to hypoxia, ischemia-reperfusion injury, and oxidative burst. Finally, the active caspase- 3 cleaves cardiac cytoskeletal proteins, such as $\alpha$-actin, $\alpha$-actinin, $\alpha / \beta$-myosin heavy chain, myosin light chain $1 / 2$, tropomyosin and troponins [16]; ii) the extrinsic pathway involves the stimulation of pathways mediated by death-receptors, such as the Fas receptor or the tumor necrosis factor $\alpha$ receptor-associated death domain protein (TRADD) [17]. Even if the death-receptors do not necessarily cause cell death, the binding of each deathreceptor to its ligand induces the formation of a deathinducing signaling complex (i.e.: TL1A/DR3; TRAIL/TRAILR) which activates caspase- 8 [18]. The magnitude of apoptosis into the heart is regulated through the expression of: a) anti-apoptotic factors, such as Bcl-2, XIAP (X chromosome-linked Inhibitors of Apoptotic Proteins), ARC (apoptosis regulator with caspase recruitment domain), c-FLIP(L) (an endogenous inhibitor of death receptor-induced apoptosis through the caspase-8 pathway), Foxo3a (a regulator of calcium level) and microRNA (miRNA)-702 (a downregulator of activating transcription factor 6); b) pro-apoptotic factors, such as Bax and Bak, Smac/DIABLO, XIAP-interacting protein-1 and Omi/HtrA2 (IAPs inhibitors) [19].

Oncosis, conversely, is a non apoptotic cell death characterized by rapid depletion of intracellular ATP [19], mitochondria swelling due to the failure of the surface ionic pumps and progressive plasma membrane disruption, followed by an inflammatory reaction [19]. Oncosis is a major contributor to myocardial ischemic cell death [20] and may be independent of caspases activation [20].

Although, autophagy is a process characterized by lysosome-dependent degradation and recycling of intracellular elements, such as dysfunctional mitochondria [21]. It characterizes a conservative response to different insults. Macroautophagy is the main form of autophagy, where plasma membrane enveloping a large portion of the cytosol forming the autophagosomes. The autophagosomes fuse with lysosomes to form autolysosomes [22]. Further studies also detected the occurrence of microautophagy, which is the transfer of small cytosolic components into the lysosome by membrane vesicles [23], and chaperone-mediated autophagy, which is the direct shuttling of soluble cytosolic proteins into lysosomes by chaperone (i.e.: heat shock protein of $70 \mathrm{kDa}$ ) [24].

Deregulated autophagy leads to cell death and cardiac dysfunction through uncontrolled self-digestion of cellular constituents [25]. Even if much remains to be elucidated, AMP-activated protein kinase (AMPK), an important regulator of cardiac metabolism [26], serves as an activator of myocardial autophagy through activation of E3 ligases expression [27]. miRNA-325 contributes also to promote autophagic cell death [25].

\section{THE TURNOVER OF CORONARY VESSELS}

The capillary density and the capillary-to-myocyte ratio influences the effectiveness of the myocardial blood perfusion in response to increasing load, which is critical to support cardiac contractile function [28]. The rarefaction as well as the dysfunction of the microcirculatory net following myocardial ischemia impairs the restoration of the blood supply in infarcted myocardium [29]. The capillary density is maintained by a balanced turnover of endothelial cells proliferation and migration, sprouting and tube formation. New coronary microvessels are generated from pre-existing mature endothelial cells in response to different sig- 
nals, such as hypoxia [30], oxygen free radicals (ROS) [31], growth factors (VEGF, HGF, FGF, Notch-1 and PDGF- $\beta$ ) [16,32], C-type natriuretic peptide [33] or nitric oxide (NO) [34]. Conversely, the coronary angiogenesis is hampered by chronic inhibition of endothelial NO synthase [35] and by different soluble factors. The main endogenous inhibitors of angiogenesis are angiostatin, endostatin [36] and miRNA-24 [37].

Interestingly, the endothelial ability to renew the capillary network architecture is controlled via cell-matrix mechanical interactions [38] and shear stress [39].

\section{THE TURNOVER OF EXTRACELLULAR MATRIX}

The turnover of cardiac extracellular matrix (ECM) provides a balance of elastic and plastic structures supporting cardiomyocytes, interstitial cells and capillaries in order to optimize the mechanotransduction, the electrical conductivity and permittivity, the intercellular cross-talk, and metabolic activity in the presence of different microenvironment [40]. This issue is critical because the features of ECM change during early and late remodeling process. In particular, glycosaminoglycans (i.e: heparan sulfate, hyaluronan), glycoproteins (i.e: tenascin-C) and proteoglycans (i.e.: lumican) play a key role in ECM formation [40]. Extracellular Granzyme B and metalloproteinases (MMPs), bioactive serine proteases, contribute to the loss of myocardial structural integrity through cleavage of ECM proteins [41,42]. Other factors may interfere with the renew of ECM in normal heart and with fibrosis during remodelling. In particular, the connective tissue growth factor (CTGF), a secreted cysteine-rich protein, highly expressed in both cardiac fibroblasts and cardiomyocytes of failing heart [43], enhances the expression of fibronectin and collagen type 1 through the activation of TGF-beta-dependent pathways. Finally, CTGF expression is epigenetically down regulated by selective microRNAs, such as miRNA-133 and miRNA-30 [44].

\section{THE INNATE IMMUNITY APPARATUS: CROSS-TALK BETWEEN MYOCARDIAL SENSORS}

Innate immune apparatus triggers inflammatory response. In particular, toll-like receptor-mediated pathways and cardiac progenitor cells modulate the release of soluble auto-/paracrine factors, such as chemokines, cytokines and exosomes in the injured heart [45].

Cardiac progenitor cells, endothelial cells, fibroblasts and mast cells, which are resident in the adult heart [46], express auto-/paracrine mediators able to activate or to silence gene profile and function in response to changes of microenvironment and tissue geometry [32].

Toll-like receptors (TLRs), such as TLR-2, TLR-3 and TLR-4, are recognition receptors expressed by all cells resident into the adult heart and mediates immune-mediated pathways activity during myocardial remodelling [47]. Endogenous products of myocardial remodelling, such as free radicals, heat shock proteins and hyaluronan, activate several kinases and NF-kB through TLRs, which promote the expression of inflammatory mediators [47] acting as endogenous preconditioning agents [48].

Even though clinical trials have reported unconvincing results on the renew of cardiomyocytes in infarcted myocardium by progenitor/stem cells [49], cardiac progenitor cells are able to polarize human macrophages into an anti-inflammatory phenotype promoting the release of angiogenic and anti-inflamamtory cytokines, such as VEGF, IL-10 and IL-13, to inhibit the release of pro-inflammatory cytokines, such as IL-1 $\alpha$, IL-17 and interferon gamma [50] and to induce the release of membrane-surrounded nanovesicles, termed exosomes, activating pro-survival signaling pathways in cardiomyocytes involving TLR 4 and HSP27 (48). This mechanism highlights the role of myocardial progenitor cells as critical regulator of cell-to-cell communication in the adaptive response of cardiac cells to ischemic microenvironment [51].

\section{EPIGENETIC MODULATION OF CARDIOPROTECTION}

The epigenetic code refers to specific heritable chromatin-based regulatory mechanisms underlie the regulation of gene expression without altering DNA sequence [52]. Epigenetic pathways mediate the transcriptional and post-transcriptional modifications of gene profile also in cardiac cells. Three main pathways regulate the epigenetic state of the heart: DNA methylation, histone modifications, and RNA-based silencing.

DNA methylation refers mainly to the addition of a methyl group to the 5-position of cytosine of CpG sequence of promoter regulatory regions through selective enzymes [5]. The cells use DNA methylation to lock gene trascription in the off position by three mechanisms: i) the blocking of recruitment of transcription factors to correspondent cis-DNA binding elements by steric hindrance, ii) the specific co-binding of proteins to methylated DNA that compete with the specific transcriptional factors [53] and iii) the recruitment of histone deacetylases (HDACs) to silence gene expression [54]. The gene donwregulation through the global gene promoter methylation is a typical feature of the end-stage failing myocardium in humans [55].

Histone modifications alter the gene expression through changes in the nucleosome conformation in 
order to control DNA accessibility. The nucleosome represents the chromatin unit and is composed of 146-bp DNA wrapped around octamers formed of four couple of different highly alkaline nuclear proteins termed histones (H2A, H2B, H3, and H4). Histones undergo to different posttranslational modifications at level of lysine (acetylation, ubiquitination, methylation, sumolyation) or arginine (methylation) or serine and threonine (phosphorylation) residues [5]. Reversible histone acetylation plays a key role in the development of postischemic myocardial remodelling. The magnitude of myocardial histone acetylation, which usually activates gene transcription, is regulated by the balance of the activity of two different enzymes: a) histone acetlytransferase (HAT), such as p300/CREB-binding protein, which transfers acetyl group to histones and prevent chromatin compaction, and b) histone deacetylase (HDAC), which removes acetyl group from conserved lysine residues of $\mathrm{H} 3$ and $\mathrm{H} 4$ histone and leads to the formation of unreadable chromatin. There are four major classes of HDACs, which randomly act to control gene expression in cardiac cells exposed to hostile microenvironment. We and other investigators have demonstrated that the inhibition of the class I HDACs in cardiac cells is able to inhibit apoptosis and to stimulate angiogenesis through acetylation of $\mathrm{H} 4$ histone. Taken together, these biological events limit structural remodelling and improve the cardiac function in vivo $[6,56]$. Finally, phosphorylation of histone $\mathrm{H} 2 \mathrm{~A}(\mathrm{X})$ is essential to repair damaged DNA [57]; although, phosphorylation of histone $\mathrm{H} 3$ promotes cell proliferation and promotes gene transcription through acetylation of $\mathrm{H} 3 \mathrm{~K} 14$ by the Gcn 5 acetyltransferase [58].

MicroRNA (miRNAs) and the RNA interference machinery are endogenous key repressors of chromatinbased gene expression [5]. Most miRNAs genes are located at level of the intergenic, intronic, or exonic regions of DNA and are transported from the nucleus to the cytoplasm as part of mRNA. The mature miRNAs are incorporated into a miRNA-induced silencing complex (RISC) and base-paired to target mRNA for mRNA degradation [59]. Cells secrete miRNAs, small non-coding RNA molecules, into exosomes [60]. To date, it is known that miRNAs profile is altered in failing myocardium [61], which plays a key role in the impairment of the cardiac structure-function relationship. In fact, the upregulation of miRNA25 in failing heart delays myocytes calcium uptake and causes decay of contractility in vivo [62]. Similarly, the over-expression of miRNA 30c and miRNA 155 promote cell loss through alteration of the mitochondrial function [63]. miRNA 21 mediates fibroblast survival and proliferation [64]; although, miRNA2 1 * delivered to cardiomyocytes through fibroblast-derived exosomes induce hypertrophy in response to hostile microenvironment [65]. Other miRNAs might play an activator role in promoting myocyte proliferation in murine infarcted heart. For example, the myocardial overexpression of miRNA 590 and miRNA 199a promote cardiomyocyte proliferation and almost complete recovery of cardiac functional parameters in murine infarcted heart [66]. We have demonstrated that exosomal miRNA 210 prevents cardiomyocytes apoptosis in infarcted heart through downregulation of its known targets, ephrin A3 and protein-tyrosine phosphatase IB (PTPIb); although, exosomal miRNA 132 enhances the formation of mature coronary vessels through downregulation of RasGAP-p120 [60].

\section{PRIMARY PREVENTION WITH FUNCTIONAL FOODS}

Primary prevention of cardiac dysfunction is based on the avoidance or attenuation of risk factors in healthy people.

The main risk factors promoting myocardial injury are age, gender, lifestyle factors (i.e.: lower physical activity, occupational stress, smoking, excessive caloric an salt intake, excessive alcohol and coffee consumption, lower socioeconomic status) and comorbidities (i.e.: hypertension, diabetes, obesity, hyperlipidemia, depression and valvular heart disease) [67]. Even if some risk factors cannot be avoided, such as age, gender and genetic susceptibility to cardiomyopathy, lifestyle risk factors and comorbidities might be modulated by intake of functional foods, such as plant or marine foods, which contain higher amount of bioactive compounds (nutraceuticals).

\section{Foods lowering hypertension}

In young subject, the diastolic blood pressure is a risk factor for HF more relevant than systolic blood pressure; although, the impact of systolic blood pressure increases in older patients [1]. Despite the conventional anti-hypertensive medications are effective in normalizing blood pressure with combination of two or more drugs, natural dietary compounds are emerging as inhibitor of vascular and myocardial remodelling following the exposure to high blood pressure. Recent double-blind randomised placebo-controlled trials have demonstrated that the daily intake of non-fresh garlic extract (at average dose of $2.4 \mathrm{mg} /$ day for 12 weeks) causes a significant reduction of the mean systolic blood pressure in patients with refractory systolic hypertension [68]. The anti-hypertensive effects of garlic is partly due to production of NO [69]. However, so far, there is no clinically relevant evidence to claim that regular garlic intake reduces the risk of mortality and cardiovascular morbidity in hypertensive patients [70].

Other pilot study has shown that oral pea protein hydrolysate has a weak and significant blood pressurelowering effect in hypertensive subjects through inhibition of renin and angiotensin converting enzyme [71]. Conversely, no blood pressure-lowering effect was observed in hypertensive patients following di- 
etary intake of theobromine-enriched flavanol-rich chocolate [72], with known antioxidant properties. Relevant clinical research activity has shown that the most potent dietary antihypertensive compound is the n-3 fatty acid $\alpha$-linolenic acid (ALA) [73], which is contained at higher concentration in flaxseed [74]. Randomized, double-blinded, controlled trial confirmed that intake of $30 \mathrm{~g}$ of milled flaxseed/day for 6 months significantly reduces the systolic blood pressure and the risk of ventricular remodelling in hypertensive patients [75]. In fact, high plasma ALA levels inhibit soluble epoxide hydrolase and reduces circulating level of oxylipins, which cause endothelial dysfunction and atherosclerosis [76].

\section{Foods lowering hyperlipidemia}

Hyperlipidemia, in particular high levels of nonhigh-density lipoprotein cholesterol, is a primary risk factor for myocardial injury [77]. Since the progression of myocardial injury towards heart failure depends on the time exposure to hyperlipidemia, it is conceivable to prevent myocardial injury through diet supplementation with specific functional foods lowering lipids in the bloodstream.

Recent randomized controlled clinical trials have demonstrated that daily intake of functional foods containing high levels of plant-derived protein hydrolysates and peptides reduces the circulating cholesterol levels in a dose-dependent manner [78]. In particular, regular intake of plant stanols and sterols (2 g/day) [79], barley $\beta$-glucans (3 g/day) [80] or tree nuts $[81,82]$ reduces circulating LDL-cholesterol (LDL-c) serum levels. In hyperlipidemic patients, 6-months intake of diet containing both of the abovementioned compounds was more effective in LDL-C lowering compared to the intake of low-saturated fat diet [83]. Therefore, the hypocholesterolemic effects of these compounds are independent of the caloric intake. Other dietary plantderived compounds normalize the lipid profile in dislipidemic patients with normal cardiac function. For example, pectin with high molecular weight and high degree of esterification (contained in lemon and apple), when taken at dose of $6 \mathrm{~g} /$ day for 3 weeks, are effective in reducing LDL-c levels in mildly hypercholesterolemic patients [84]. Similarly, red grape seed extract, when consumed at dose of $200 \mathrm{mg} /$ day for $\mathbf{8}$ weeks, decreases both the oxidized-LDL levels and the risk of atherosclerosis and cardiovascular disorders in mild hyperlipidemic subjects [85]. Grape seeds contain high levels of flavonoids, such as gallic acid and procyanidins, with epigenetic properties (HAT inhibitors) [86]. Conversely, the cholesterol-lowering effects of phenolic-rich virgin olive oil, which is an important component of the Mediterranean diet, are still controversial and need further investigations [87]. This finding is surprising if we consider that a Mediterranean diet supplemented with extra-virgin olive oil or nuts reduces the incidence of major cardiovascular events in persons at high cardio- vascular risk [88]. Similarly, some animal-derived functional foods have shown significant effects in reducing human cardiovascular risk due to exposure to hyperlipidemia. Recent randomized placebo-controlled study has demonstrated that daily intake for 10 weeks of yoghurt supplemented with $3 \mathrm{~g}$ of $\mathrm{n}-3$ long-chain polyunsaturated fatty acids (PUFA) significantly reduced the circulating levels of inflammatory mediators and the cardiovascular risk in mildly hypertriacylglycerolemic patients [89]. The comparison between the cholesterollowering efficacy of plant- and animal-derived foods remain to be fully assessed. So far, it is known that long-term dietary intake of fish oil ( $17 \mathrm{~g} /$ day for 8 weeks), which is rich of n-3 PUFA, decreases only triglyceride serum levels in patients with metabolic syndrome; although, the dietary intake of similar dose of echium oil, a plant extract of Echium plantagineum rich of stearidonic acid, causes a marked reduction of serum triglyceride and oxidized LDL in the same class of patients [90].

\section{Foods restoring insulin sensitivity}

The insulin resistance (IR) strongly characterizes the type 2 diabetes as well as the more complex metabolic syndrome, which are independent risk factors for HF. Recent findings confirmed that chronic insulin resistance itself impairs cardiac homeostasis through the induction of inflammatory and oxidative burst related to the metabolic myocardial state following endothelial dysfunction [91]. Conventional therapies for insulin resistance partly fail to prevent and to reverse both high fasting plasma glucose and myocardial injury. Therefore, it is conceivable to develop innovative dietary-based strategies against IR based on the intake of functional foods [92]. It has been demonstrated that daily intake for one month of both whole and fractionated pea flour ( $50 \mathrm{~g} /$ day) is effective in reducing IR in overweight patients with metabolic syndrome [93]. Similarly, the daily supplementation of low cholesterol diet with $40 \mathrm{~g}$ of ground flaxseed-containing baked products improves the insulin sensitivity in hyperlipidemic adults [94]. The IR-lowering effects were observed in obese population with pre-diabetes and in patients with metabolic syndrome long-term treated with plant-derived n-3 ALA (flaxseed, rapeseed oil) [95,96].

Even though the benefits require further investigations, the use of antioxidants seems to be a promising approach to reduce the insulin resistance in an epigenetic manner. In fact, long-term dietary intake of broccoli sprouts powder (10 g/day), which contains high levels of sulphoraphane, a potent inhibitor of class I HDACs, significantly reduces serum insulin levels and homoeostasis model assessment of IR (HOMA-IR) index in type 2 diabetic patients [97]. However, further studies are mandatory to exclude the inhibition of glucose-induced insulin secretion after the long-term intake of lower dose of sulphoraphane [98]. 


\section{SECONDARY PREVENTION WITH FUNCTIONAL FOODS}

Secondary prevention of cardiac dysfunction is focused on the prevention of late myocardial remodelling in patients with current symptoms of ischemic heart diseases (i.e.: angina, myocardial infarction, recipients of coronary revascularisation, cardiac amyloidosis, arrhythmias) or with symptoms of other vascular diseases (such as stroke, peripheral vascular diseases). The aim of secondary prevention is to prevent progression of the primary myocardial injury. The conventional interventions of secondary prevention are based on drugs (i.e.: low dose aspirin, statins, $\beta$-blockers, angiotensin converting enzyme (ACE) inhibitors, inhibitors of platelet aggregation) and changes of lifestyle habits (i.e.: physical activity, diet, meticulous control of blood pressure and glucose, cognitive activity). Emerging pre-clinical evidences have shown that regular intake of selected functional foods might hamper the post-ischemic myocardial remodelling in damaged hearts. Flavonoids, such as anthocyanins, are common anti-oxidant compounds of plant-derived functional foods and their regular intake after ischemia-reperfusion injury improves cardiac function in rats [99]. Similar benefits are induced with shortterm oral administration of beta-glucan in a swine model of myocardial ischemia/reperfusion [100] and in a canine model of myocardial infarction [101]. In addition, short-term dietary intake of cooked broccolis can limit the infarct size of murine hearts exposed to ischemia-reperfusion injury [102]. While the mechanisms are still under investigation, it is conceivable that the cardioprotection is due to the inhibition of class I HDACs by sulphoraphanes contained in broccolis [103]. We have demonstrated that long-term treatment of cultured endothelial cells and Tg ( $k d r l: E G F P$ ) s843Tg zebrafish embryos with $3 \%$ barley beta-glucan enhances the formation of new vessels in the presence of ischemic microenvironment through the increased acetylation of histone $\mathrm{H} 4$, which is related to higher levels of manganese superoxide dismutase, a key antioxidant enzyme, and NO [104]. Similarly, our recent preliminary data have shown that the long-term intake of low-fat diet supplemented with functional pasta delivering 3\% barley beta-glucan increases the VEGFmediated myocardial capillary density and attenuates the ischemia/reperfusion injury in murine heart through the increase of native collateral formation after 5 -weeks of diet [105]. In addition to these recent preclinical evidences, placebo-controlled, double-blind randomised clinical trial has demonstrated that the supplementation of diet with vitamin $\mathrm{D}$, able to induce hitone acetylation and DNA demethylation [106], did not improve the endothelial function in patients with myocardial infarction [107]. It is conceivable that this negative finding is related to the hormetic regulation of the epigenetic state. In fact, the co-treatment of cells with active vitamin D, HDACs inhibitors and DNA methyltransferase inhibitors induces apoptosis of cancer cells [108], an effect induced by the exposure to highest dose of chromatin openers. Similarly, the broad use of antioxidants increases the risk of HF in patients with acute myocardial ischemia [109]. These findings suggest that the cardioprotective efficacy of functional foods mainly depends on the epigenetic magnitude of natural compounds in the presence of different microenvironment, but it does not depend on antioxidant activity. Finally, the epigenetic role of dietary antioxidant compounds in modulating the expression of myocardial microRNAs is emerging. The synergistic action of antioxidant resveratrol, a constituent of red wine, and alpha-tocotrienol, a compound of palm oil, is able to increase the myocardial expression of antiangiogenic miRNA20b, which is not reflected in the cardioprotection against ischemia/reperfusion injury [110]. In fact, other investigators have demonstrated that the anti-angiogenic properties of the resveratrol are counteracted by its ability to increase NO-dependent vasodilation [111]. Otherwise, the intake of antiinflammatory curcuminoids $(4 \mathrm{~g} /$ day from 3 days before until 5 days after the surgery), polyphenols able to demethylate the DNA [112], prevented the onset of myocardial infarction in 121 patients undergoing coronary artery bypass grafting [113]. Experimental and clinical investigations are on-going in order to further unravel epigenetic mechanisms underlie cell-to-cell and cell-to-matrix interactions in injured hearts, which are candidate targets of dietary bioactive compounds.

\section{CONCLUSIONS AND PERSPECTIVES}

Dietary functional compounds have been gaining interest, so far. Since the relationship between epigenetic state and myocardial remodelling becomes more welldefined, the identification of key molecular targets is helping to reveal new natural epigenetic compounds mainly contained in conventional plant-derived foods. These findings will be useful to design hitherto unexpected dietary approach in order to prevent both the myocardial injury and the development towards heart failure. Moreover, some relevant issues on pleiotropic epigenetic effects of natural compounds will also encourage further studies in order to reduce the dose of conventional drugs and to improve the outcome of subjects exposed to high cardiovascular risks.

\section{REFERENCES}

1. Braunwald E. Heart failure. JACC Heart Fail 2013;1:1-20.

2. Kristensen SD, Knuuti J, Saraste A, et al. 2014 ESC/ESA Guidelines on non-cardiac surgery: cardiovascular assessment and man- 
agement: The Joint Task Force on non-cardiac surgery: cardiovascular assessment and management of the European Society of Cardiology (ESC) and the European Society of Anaesthesiology (ESA). Eur Heart J 2014;35:2383-431.

3. Goldfinger JZ, Nair AP. Myocardial recovery and the failing heart: medical, device and mechanical methods. Ann Glob Health 2014;80:55-60.

4. Heusch $G$, Libby P, Gersh B, et al. Cardiovascular remodelling in coronary artery disease and heart failure. Lancet 2014;383:1933-43.

5. Matteucci M, Papini G, Ciofini E, et al. Epigenetic regulation of myocardial homeostasis, self-regeneration and senescence. Curr Drug Targets 2015;16:827-42.

6. Lionetti V, Cantoni S, Cavallini $C$, et al. Hyaluronan mixed esters of butyric and retinoic acid affording myocardial survival and repair without stem cell transplantation. J Biol Chem 2010;285:9949-67.

7. Sirtori CR, Galli C, Anderson JW, et al. Functional foods for dyslipidaemia and cardiovascular risk prevention. Nutr Res Rev 2009;22:244-61.

8. Sutton $M G$, Sharpe N. Left ventricular remodeling after myocardial infarction: pathophysiology and therapy. Circulation 2000;101: 2981-8.

9. Bergmann $O$, Bhardwaj RD, Bernard $S$, et al. Evidence for cardiomyocyte renewal in humans. Science 2009;324:98-102.

10. Lionetti $V$, Matteucci $M$, Ribezzo $M$, et al. Regional mapping of myocardial hibernation phenotype in idiopathic end-stage dilated cardiomyopathy. J Cell Mol Med 2014;18:396-414.

11. Prescimone T, Lionetti V, Cabiati $M$, et al. Apoptotic transcriptional profile remains activated in late remodeled left ventricle after myocardial infarction in swine infarcted hearts with preserved ejection fraction. Pharmacol Res 2013;70:41-9.

12. Prescimone $T$, Lionetti $V$, Caselli $C$, et al. Severity of regional myocardial dysfunction is not affected by cardiomyocyte apoptosis in non-ischemic heart failure. Pharmacol Res 2011;63:207-15.

13. Forini $F$, Lionetti $V$, Ardehali $H$, et al. Early long-term $L-T 3$ replacement rescues mitochondria and prevents ischemic cardiac remodelling in rats. J Cell Mol Med 2011;15:514-24.

14. Zentilin L, Puligadda U, Lionetti V, et al. Cardiomyocyte VEGFR1 activation by VEGF-B induces compensatory hypertrophy and preserves cardiac function after myocardial infarction. FASEB $J$ 2010;24:1467-78.

15. Kostin S. Types of cardiomyocyte death and clinical outcomes in patients with heart failure. J Am Coll Cardiol 2011;57:1532-4.

16. Communal $C$, Sumandea $M$, de Tombe $P$, et al. Functional consequences of caspase activation in cardiac myocytes. Proc Natl Acad Sci USA 2002;99:6252-6.

17. Pobezinskaya $Y L$, Liu $Z$. The role of TRADD in death receptor signalling. Cell Cycle 2012;11:871-6.

18. Czerski L, Nuñez G. Apoptosome formation and caspase activation: is it different in the heart? J Mol Cell Cardiol 2004;37:643-52.

19. Majno G, Joris I. Apoptosis, oncosis, and necrosis. An overview of cell death. Am J Pathol 1995;146:3-15.

20. Weerasinghe P, Buja LM. Oncosis: an important non-apoptotic mode of cell death. Exp Mol Pathol 2012;93:302-8.

21. Mei Y, Thompson MD, Cohen RA, Tong X. Autophagy and oxidative stress in cardiovascular diseases. Biochim Biophys Acta 2015;1852:243-51.

22. Hamacher-Brady A, Brady NR, Gottlieb RA. Enhancing macroautophagy protects against ischemia/reperfusion injury in cardiac myocytes. J Biol Chem 2006;281:29776-87.

23. Kunz JB, Schwarz H, Mayer A. Determination of four sequential stages during microautophagy in vitro. J Biol Chem 2004;279: 9987-96.

24. Dice JF. Chaperone-mediated autophagy. Autophagy 2007;3:295-9.
25. Bo L, Su-Ling D, Fang L, et al. Autophagic program is regulated by miR-325. Cell Death Differ 2014,21:967-77.

26. Horman S, Beauloye C, Vanoverschelde JL, Bertrand L. AMP-activated protein kinase in the control of cardiac metabolism and remodeling. Curr Heart Fail Rep 2012;9:164-73.

27. Baskin KK, Taegtmeyer, H. AMP-activated protein kinase regulates E3 ligases in rodent heart. Circ Res 2011;109:1153-61.

28. Turek Z, Hoofd L, Rakusan K. Myocardial capillaries and tissue oxygenation. Can J Cardiol 1986;2:98-103.

29. van der Laan AM, Piek JJ, van Royen N. Targeting angiogenesis to restore the microcirculation after reperfused MI. Nat Rev Cardiol 2009;6:515-23.

30. Vilar J, Waeckel L, Bonnin P, et al. Chronic hypoxia-induced angiogenesis normalizes blood pressure in spontaneously hypertensive rats. Circ Res 2008;103:761-9.

31. West XZ, Malinin NL, Merkulova AA, et al. Oxidative stress induces angiogenesis by activating TLR2 with novel endogenous ligands. Nature 2010;467:972-9.

32. Lionetti V, Bianchi G, Rechia FA, Ventura C. Control of autocrine and paracrine myocardial signals: an emerging therapeutic strategy in heart failure. Heart Fail Rev 2010;15:531-42.

33. Del Ry S, Cabiati M, Martino A, et al. High concentration of Ctype natriuretic peptide promotes VEGF-dependent vasculogenesis in the remodeled region of infarcted swine heart with preserved left ventricular ejection fraction. Int J Cardiol 2013;168:2426-34.

34. Zhao $X, L u X$, Feng Q. Deficiency in endothelial nitric oxide synthase impairs myocardial angiogenesis. Am J Physiol Heart Circ Physiol 2002;283:H2371-8.

35. O'Riordan E, Mendelev N, Patschan S, et al. Chronic NOS inhibition actuates endothelial-mesenchymal transformation. Am J Physiol Heart Circ Physiol 2007;292:H285-94

36. Nikolova A, Ablasser K, Wyler von Ballmoos MC, et al. Endogenous angiogenesis inhibitors prevent adaptive capillary growth in left ventricular pressure overload hypertrophy. Ann Thorac Surg 2012;94:1509-17.

37. Fiedler J, Jazbutyte V, Kirchmaier BC, et al. MicroRNA-24 regulates vascularity after myocardial infarction. Circulation 2011;124:720-30

38. Sun J, Jamilpour N, Wang FY, Wong PK. Geometric control of capillary architecture via cell-matrix mechanical interactions. Biomaterials 2014;35:3273-80.

39. Galie PA, Nguyen DH, Choi CK, et al. Fluid shear stress threshold regulates angiogenic sprouting. Proc Natl Acad Sci USA 2014;111:7968-73.

40. Li AH, Liu PP, Villarreal FJ, Garcia RA. Dynamic changes in myocardial matrix and relevance to disease: translational perspectives. Circ Res 2014;114:916-27.

41. Boivin WA, Shackleford M, Vanden Hoek A, et al. Granzyme B cleaves decorin, biglycan and soluble betaglycan, releasing active transforming growth factor- $\beta 1$. PLoS One 2012;7:e331-63.

42. Vanhoutte D, Heymans, S. TIMPs and cardiac remodeling: embracing the MMP-independent-side of the family. J Mol Cell Cardiol 2010;48:445-53.

43. Koshman YE, Patel N, Chu M, et al. Regulation of connective tissue growth factor gene expression and fibrosis in human heart failure. J Card Fail 2013;19:283-94.

44. Duisters RF, Tijsen AJ, Schroen B, et al. miR-133 and miR-30 regulate connective tissue growth factor: implications for a role of microRNAs in myocardial matrix remodeling. Circ Res 2009;104: 170-8.

45. Frangogiannis NG. The inflammatory response in myocardial injury, repair, and remodelling. Nat Rev Cardiol 2014;11:255-65.

46. Triggiani M, Patella V, Staiano RI, et al. Allergy and the cardiovascular system. Clin Exp Immunol 2008;153:7-11. 
47. Vallejo JG. Role of toll-like receptors in cardiovascular diseases. Clin Sci (Lond) 2011;121:1-10.

48. Vicencio JM, Yellon DM, Sivaraman $V$, et al. Plasma exosomes protect the myocardium from ischemia-reperfusion injury. $J$ Am Coll Cardiol 2015;65:1525-36.

49. Barile L, Lionetti V. Prometheus's heart: what lies beneath. J Cell Mol Med 2012;16:228-36.

50. Adutler-Lieber S, Ben-Mordechai T, Naftali-Shani $N$, et al. Human macrophage regulation via interaction with cardiac adipose tissue-derived mesenchymal stromal cells. J Cardiovasc Pharmacol Ther 2013;18:78-86.

51. Lionetti $V$. How resident stem cells communicate with cardiac cells in beatingheart? J.Stem Cell Res Ther 2011;1:e104.

52. Berger SL, Kouzarides T, Shiekhattar $R$, Shilatifard A. An operational definition of epigenetics. Genes Dev 2009;23:781-3.

53. Boyes J, Bird AP. DNA methylation inhibits transcription indirectly via a methyl-CpG binding protein. Cell 1991;64:1123-34.

54. Cameron EE, Bachman KE, Myohanen S, et al. Synergy of demethylation and histone deacetylase inhibition in the re-expression of genes silenced in cancer. Nat Genet 1999;21:103-7.

55. Movassagh M, Choy MK, Knowles DA, et al. Distinct epigenomic features in end-stage failing human hearts. Circulation 2011;124:2411-22.

56. Kao YH, Liou JP, Chung CC, et al. Histone deacetylase inhibition improved cardiac functions with direct antifibrotic activity in heart failure. Int J Cardiol 2013;168:4178-83.

57. Celeste A, Fernandez-Capetillo O, Kruhlak MJ, et al. Histone $H 2 A X$ phosphorylation is dispensable for the initial recognition of DNA breaks. Nat Cell Biol 2003;5:675-9.

58. Rossetto D, Avvakumov N, Côté J. Histone phosphorylation: a chromatin modification involved in diverse nuclear events. Epigenetics 2012;7:1098-108.

59. Gregory RI, Chendrimada TP, Cooch N, Shiekhattar R. Human RISC couples microRNA biogenesis and posttranscriptional gene silencing. Cell 2005;123:631-40.

60. Barile L, Lionetti V, Cervio $E$, et al. Extracellular vesicles from human cardiac progenitor cells inhibit cardiomyocyte apoptosis and improve cardiac function after myocardial infarction. Cardiovasc Res 2014;103:530-41.

61. Leptidis S, El Azzouzi H, Lok SI, et al. A deep sequencing approach to uncover the miRNOME in the human heart. PLOS ONE 2013;8:e57800.

62. Wahlquist $C$, Jeong D, Rojas-Muñoz A, et al. Inhibition of miR25 improves cardiac contractility in the failing heart. Nature 2014;508:531-5.

63. Wijnen WJ, van der Made I, van den Oever S, et al. Cardiomyocyte-Specific miRNA-30c over-expression causes dilated cardiomyopathy. PLoS One 2014;9:e96290.

64. Thum T, Gross C, Fiedler J, et al. MicroRNA-21 contributes to myocardial disease by stimulating MAP kinase signalling in fibroblasts. Nature 2008;456:980-4.

65. Bang C, Batkai S, Dangwal S, et al. Cardiac fibroblast-derived microRNA passenger strand-enriched exosomes mediate cardiomyocyte hypertrophy. J Clin Invest 2014;124:2136-46.

66. Eulalio A, Mano M, Dal Ferro M, et al. Functional screening identifies miRNAs inducing cardiac regeneration. Nature 2012;492: 376-81.

67. Butler J. Primary prevention of heart failure. ISRN Cardiol 2012:982417.

68. Ried K, Frank OR, Stocks NP. Aged garlic extract reduces blood pressure in hypertensives: a dose-response trial. Eur J Clin Nutr 2013;67:64-70.

69. Al-Qattan KK, Thomson M, Al-Mutawa'a S, et al. Nitric oxide mediates the blood-pressure lowering effect of garlic in the rat two-kid- ney, one-clip model of hypertension. J Nutr 2006;136:S774S-6.

70. Stabler SN, Tejani AM, Huynh F, Fowkes C. Garlic for the prevention of cardiovascular morbidity and mortality in hypertensive patients. Cochrane Database Syst Rev 2012;8:CD007653.

71. Li H, Prairie N, Udenigwe CC, et al. Blood pressure lowering effect of a pea protein hydrolysate in hypertensive rats and humans. $J$ Agric Food Chem 2011;59:9854-60.

72. van den Bogaard B, Draijer $R$, Westerhof BE, et al. Effects on peripheral and central blood pressure of cocoa with natural or highdose theobromine: a randomized, double-blind crossover trial. Hypertension 2010;56:839-46.

73. Rajaram $S$. Health benefits of plant-derived $\alpha$-linolenic acid. Am J Clin Nutr 2014;100:S443-8.

74. Rodriguez-Leyva D, Weighell W, Edel AL, et al. Potent antihypertensive action of dietary flaxseed in hypertensive patients. Hypertension 2013;62:1081-9.

75. Caligiuri SP, Aukema HM, Ravandi A, et al. flaxseed consumption reduces blood pressure in patients with hypertension by altering circulating oxylipins via an $\alpha$-linolenic acid-induced inhibition of soluble epoxide hydrolase. Hypertension 2014;64:53-9.

76. Bassett CM, McCullough RS, Edel AL, et al. The $\alpha$-linolenic acid content of flaxseed can prevent the atherogenic effects of dietary trans fat. Am J Physiol Heart Circ Physiol 2011;301:H2220-6.

77. Boekholdt SM, Arsenault BJ, Mora S, et al. Association of LDL cholesterol, non-HDL cholesterol, and apolipoprotein B levels with risk of cardiovascular events among patients treated with statins: a meta-analysis. JAMA 2012;307:1302-9.

78. Chen ZY, Jiao R, Ma KY. Cholesterol-lowering nutraceuticals and functional foods. J Agric Food Chem 2008;56:8761-73.

79. Gylling H, Plat J, Turley S, et al. Plant sterols and plant stanols in the management of dyslipidaemia and prevention of cardiovascular disease. Atherosclerosis 2014;232:346-60.

80. Rondanelli M, Opizzi A, Monteferrario F, et al. Beta-glucan-or rice bran-enriched foods: a comparative crossover clinical trial on lipidic pattern in mildly hypercholesterolemic men. Eur J Clin Nutr 2011;65:864-71.

81. Orem A, Yucesan FB, Orem C, et al. Hazelnut-enriched diet improves cardiovascular risk biomarkers beyond a lipid-lowering effect in hypercholesterolemic subjects. J Clin Lipidol 2013;7:123-31.

82. O'Neil CE, Keast DR, Nicklas TA, Fulgoni VL 3rd. Nut consumption is associated with decreased health risk factors for cardiovascular disease and metabolic syndrome in U.S. adults: NHANES 1999-2004. J Am Coll Nutr 2011;30:502-10.

83. Jenkins DJ, Jones PJ, Lamarche B, et al. Effect of a dietary portfolio of cholesterol-lowering foods given at 2 levels of intensity of dietary advice on serum lipids in hyperlipidemia: a randomized controlled trial. JAMA 2011;306:831-9.

84. Brouns F, Theuwissen E, Adam A, et al. Cholesterol-lowering properties of different pectin types in mildly hyper-cholesterolemic men and women. Eur J Clin Nutr 2012;66:591-9.

85. Razavi SM, Gholamin S, Eskandari A, et al. Red grape seed extract improves lipid profiles and decreases oxidized low-density lipoprotein in patients with mildhyperlipidemia. J Med Food 2013;16: 255-8.

86. Choi KC, Park S, Lim BJ, et al. Procyanidin B3, an inhibitor of histone acetyltransferase, enhances the action of antagonist for prostate cancer cells via inhibition of p300-dependent acetylation of androgen receptor. Biochem J 2011;433:235-44.

87. Damasceno NR, Pérez-Heras A, Serra M, et al. Crossover study of diets enriched with virgin olive oil, walnuts or almonds. Effects on lipids and other cardiovascular risk markers. Nutr Metab Cardiovasc Dis 2011;21:S14-20.

88. Estruch $R$, Ros E, Salas-Salvadó J, et al. Primary prevention of cardiovascular disease with a Mediterranean diet. N Engl J Med 2013;368:1279-90. 
89. Dawczynski C, Massey KA, Ness C, et al. Randomized placebo-controlled intervention with n-3 LC-PUFA-supplemented yoghurt: effects on circulating eicosanoids and cardiovascular risk factors. Clin Nutr 2013;32:686-96.

90. Kuhnt K, Fuhrmann C, Köhler M, et al. Dietary echium oil increases long-chain n-3 PUFAs, including docosapentaenoic acid, in blood fractions and alters biochemical markers for cardiovascular disease independently of age, sex, and metabolic syndrome. J Nutr 2014;144:447-60.

91. Kolwicz SC Jr, Purohit S, Tian, R. Cardiac metabolism and its interactions with contraction, growth, and survival of cardiomyocytes. Circ Res 2013;113:603-16.

92. Khan MI, Anjum FM, Sohaib M, Sameen, A. Tackling metabolic syndrome by functional foods. Rev Endocr Metab Disord 2013;14:287-97.

93. Marinangeli $C P$, Jones $P J$. Whole and fractionated yellow pea flours reduce fasting insulin and insulin resistance in hypercholesterolaemic and overweight human subjects. Br J Nutr 2011;105:110-7.

94. Bloedon LT, Balikai S, Chittams J, et al. Flaxseed and cardiovascular risk factors: results from a double blind, randomized, controlled clinical trial. J Am Coll Nutr 2008;27:65-74.

95. Hutchins AM, Brown BD, Cunnane SC, et al. Daily flaxseed consumption improves glycemic control in obese men and women with pre-diabetes: a randomized study. Nutr Res 2013;33:367-75.

96. Baxheinrich A, Stratmann B, Lee-Barkey YH, et al. Effects of a rapeseed oil-enriched hypoenergetic diet with a high content of $\alpha$ linolenic acid on body weight and cardiovascular risk profile in patients with the metabolic syndrome. Br J Nutr 2012;108: 682-91.

97. Bahadoran $Z$, Tohidi $M$, Nazeri $P$, et al. Effect of broccoli sprouts on insulin resistance in type 2 diabetic patients: a randomized double-blind clinical trial. Int J Food Sci Nutr 2012;63:767-71.

98. Fu J, Zhang Q, Woods CG, et al. Divergent effects of sulforaphane on basal and glucose-stimulated insulin secretion in $\nabla$-cells: role of reactive oxygen species and induction of endogenous antioxidants. Pharm Res 2013;30:2248-59.

99. Toufektsian MC, de Lorgeril M, Nagy N, et al. Chronic dietary intake of plant-derived anthocyanins protects the rat heart against ischemia-reperfusion injury. J Nutr 2008;138:747-52.

100. Aarsæther E, Straumbotn E, Rösner A, Busund, R. Oral $\beta$-glucan reduces infarction size and improves regional contractile function in a porcine ischaemia/reperfusion model. Eur J Cardiothorac Surg 2012;41:919-25.

101. Qian J, Liu AJ, Zhang W, et al. Protective effects of betaglucin on myocardial tissue during myocardial infarction in rats and dogs. Acta Pharmacol Sin 2009;30:1092-8.

102. Mukherjee S, Lekli I, Ray D, et al. Comparison of the protective effects of steamed and cooked broccolis on ischaemia-reperfusioninduced cardiac injury. Br J Nutr 2010;103:815-23.

103. Ho E, Clarke JD, Dashwood RH. Dietary sulforaphane, a histone deacetylase inhibitor for cancer prevention. J Nutr 2009;139:2393-6.

104. Agostini S, Chiavacci E, Matteucci M, et al. Barley beta-glucan promotes $M n S O D$ expression and enhances angiogenesis under oxidative microenvironment. J Cell Mol Med 2015;19:227-38.

105. Casieri V, Matteucci M, Agrimi J, et al. Long-term dietary intake of pasta enriched with barley (1-3) beta-d-glucan induces neovascularization-mediated cardioprotection against ischemia/reperfusion injury in mice (abstract). Vascul Pharmacol 2015;75:56.

106. Fetahu IS, Höbaus J, Kállay E. Vitamin D and the epigenome. Front Physiol 2014;5:164.

107. Witham MD, Dove FJ, Khan F, et al. Effects of vitamin D supplementation on markers of vascular function after myocardial infarction-a randomised controlled trial. Int J Cardiol 2013;167:745-9.

108. Pan L, Matloob AF, Du J, et al. Vitamin D stimulates apoptosis in gastric cancer cells in synergy with trichostatin A/sodium butyrateinduced and 5-aza-2'-deoxycytidine-induced PTEN upregulation. FEBS J 2010;277:989-99.

109. Tardif JC, McMurray JJ, Klug E, et al. Effects of succinobucol (AGI-1067) after an acute coronary syndrome: a randomised, double-blind, placebo-controlled trial. Lancet 2008;371:1761-8.

110. Mukhopadhyay P, Das S, Ahsan MK, et al. Modulation of microRNA $20 b$ with resveratrol and longevinex is linked with their potent anti-angiogenic action in the ischaemic myocardium and synergestic effects of resveratrol and $\gamma$-tocotrienol. J Cell Mol Med 2012;16:2504-17.

111. Robich MP, Chu LM, Chaudray M, et al. Anti-angiogenic effect of high-dose resveratrol in a swine model of metabolic syndrome. Surgery 2010;148:453-62.

112. Russo GL, Vastolo V, Ciccarelli M, et al. Dietary polyphenols and chromatin remodelling. Crit Rev Food Sci Nutr 2017;57:2589-99.

113. Wongcharoen W, Jai-Aue S, Phrommintikul A, et al. Effects of curcuminoids on frequency of acute myocardial infarction after coronary artery bypass grafting. Am J Cardiol 2012;110:40-4. 